\section{Making a mark - taking assessment to technology}

\author{
M. J. Cox, ${ }_{1}^{1}$ T. Schleyer, ${ }^{2}$ L. A. Johnson, ${ }^{3}$ K. A. Eaton ${ }^{4}$ and P. A. Reynolds ${ }^{5}$
}

VERIFIABLE CPD PAPER
IN BRIEF

- This paper considers the role of ICT in the assessment of students' work.

- It describes techniques that are now available and their advantages and disadvantages.

- The growing problem of plagiarism is discussed.

- The paper concludes that although ICT has much to contribute to assessment, the role of 'live' assessors is still of paramount importance.

During any course of study, students are assessed usually through a range of methods which may include written examinations, coursework assignments, professional practice, oral tests and practical examinations. This article considers the various forms of assessment in dental education and how information and communication technology is being applied to them. As innovative teaching and learning methods such as computer simulations are introduced, the assessment of results, successes and failures is taking on new forms in many traditional courses. The web is also spreading its tentacles into assessment, with the benefits of offering almost instant feedback and support. However, technology brings its own problems, not least by making ever more ingenious methods of plagiarism easier. Educational establishments, therefore, must be aware of such problems and have policies in place to counteract them.

\section{E-LEARNING IN DENTISTRY}

Section A: Teaching and technology

1. A description of the new technologies used in transforming dental education

2. Seeing is believing: dental education benefits from developments in videoconferencing

3. Webcasting: casting the web more widely

4. Top of the pops - CD-ROM and DVDs in dental education

Section B: Informatics: better informed by systems and services

5. Better informed: an overview of health informatics

6. Better informed in clinical practice a brief overview of dental informatics

7. Digital clinical records and practice administration in primary dental care

Section C: Impact of e-learning in

dental education

8. Remember the days in the old school yard: from lectures to online learning

9. An intricate web - designing and authoring a web-based course

10. The many faces of interaction

11. Supporting the learner and teacher online

12. Making a mark - taking assessment to technology

13. Continuing professional development and ICT: target practice

14. Assuring quality

Section D: A connected future

15. Nine years of DentEd: a global perspective

16. A vision of dental education in the third millenium

\title{
INTRODUCTION
}

The assessment of educational outcome is always a hot topic, as exemplified by press comment on the supposed fall in the quality of 'A' Level and degree passes. As a result it is fair to say that the media spotlight is on how examinations are marked and how students' results are measured. Undoubtedly, assessment is crucial in higher education to measure not only what students have learnt but also to gain feedback on the effectiveness of one's teaching. 'Assessment plays a critical role in the education process

Emerita Professor of ICT in Education, Department of Education and Professional Studies, School of Social Science and Public Policy, King's College London/Senior Research Fellow, King's College London Dental Institute, Floor 3, Strand Bridge House, 138-142 Strand, London, WC2 1 $1 \mathrm{HH}_{;}{ }^{2}$ Associate Professor and Director, Centre for Dental Informatics, School of Dental Medicine, University of Pittsburgh, USA; ${ }^{3}$ Professor and Director of Dental Informatics, University of Michigan School of Dentistry, Ann Arbor, Michigan, USA; ${ }^{4}$ Visiting Professor, UCL Eastman Dental Institute, 256 Gray's Inn Road, London, WC2 1HH/Honorary Professor, University of Kent; ${ }^{5}$ Professor of Dental Education, Centre for Flexible Learning in Dentistry, King's College Dental Institute, Floor 3, Strand Bridge House, 138-142 Strand, London, WC2 $1 \mathrm{HH}$

${ }^{*}$ Correspondence to: Professor P. A. Reynolds Email: P.A.Reynolds@kcl.ac.uk

\section{Refereed Paper}

DOI: $10.1038 /$ sj.bdj.2008.566

${ }^{\oplus}$ British Dental Journal 2008; 205: 33-39 as both a means of grading and supplying valuable feedback to a student. ${ }^{1}$ Furthermore, an extensive analysis of 250 academic papers $^{2}$ showed that there is clear evidence to link formative assessment with students' improved achievements. Given the pressure on rigorous assessment in higher education, many academics may consider it foolhardy to consider methods and techniques other than the tried and tested variants of written and practical examinations and assignments. In recent years, in spite of the evidence to show that formative assessment, such as coursework assignments, leads to improved student learning, researchers have also found that in many universities this method is even in decline. ${ }^{3}$ However, ICT in the form of computer-assisted assessment (CAA) brings some known advantages to ensure that it should be used as a vital component of the assessment process. CAA is sometimes referred to as CBA (computer-based assessment). For the purposes of this paper they are considered synonymous.

Like many ICT-based processes, CAA is not that new; 'Computer-based tests have been used since the 1960s to test knowledge and problem solving skills'. 
Advances in technology and teaching practice are ensuring that CAA is not just an alternative method of delivering examinations, it represents an important qualitative shift away from traditional methods such as paper based tests. ${ }^{4}$

An indication of the extent to which CAA is used can be ascertained from the Computer Assisted Assessment Centre's national survey (1999). ${ }^{5}$ At that time, in the UK, over 80 universities and colleges of higher education reported some use of CAA, predominantly for the assessment of computing science and mathematics. The majority of CAA tests were reported as being in the form of summative assessments, with less use being made of formative, self-assessment and diagnostic uses. The multiple choice questions (MCQ) format was the most widely used type of assessment, followed by multi-response and text/numeric input. Examiners were most likely to use CAA if tests were available and computerised for them, or they created the test and it was computerised by someone else.

In schools, there are also moves to introduce e-assessment by the Qualifications and Curriculum Authority (QCA), although the pilot ICT skills tests which involved complex onscreen assignments and no multiple choice questions have now been replaced with more simple multiple choice questions, especially for primary pupils (see http://www.qca.org. uk/qca_6467.aspx). The launch of the QCA's Blueprint for assessment will, if implemented widely in schools, change the expectations of students moving from schools to HE regarding the methods of assessment which they will have experienced before entering HE, with potential options such as: ${ }^{6}$

- All new qualifications will include an option for on-screen assessment

- All awarding bodies should be set up to accept and assess e-portfolios

- Ten new qualifications, specifically designed for electronic delivery and e-assessment, should be developed, accredited and go live.

It is possible that higher education may gradually follow suit, although the growing range of e-learning materials, as highlighted earlier in this series, ${ }^{7}$ is providing new ways of assessing students as part of the teaching and learning process in addition to multiple choice questions. Appropriate uses of CAA have the virtue of helping to maintain standards and consistency within a marking regime. It can also provide a rich range of formative assessment methods; provide virtually instantaneous results; make testing more efficient (through adaptive testing); and it can monitor all levels of assessment and help thwart plagiarism. Furthermore, CAA scores can be stored in an electronic portfolio (e-portfolio) thus enabling a student to view their progress over time.

e-Assessment also enables teaching staff to deal with larger numbers of students and is more efficient and secure. Given the diverse nature of CAA, students can particularly benefit from the advantages of formative assessment to monitor their individual learning, as it is easier for them to obtain immediate feedback as they progress through a particular course.

\section{ASSESSMENT DEFINED}

Assessment has been defined as 'The process of evidencing and evaluating the extent to which a candidate has met or made progress towards the assessment criteria. $^{8}$ There are two main forms of assessment, ${ }^{9}$ as discussed above: formative assessment, which is often referred to as 'assessment for learning, ${ }^{9}$ and summative assessment, which involves assessing the students' knowledge and skills after a period of teaching, eg written examinations at the end of a course.

\section{Formative assessment}

Using traditional methods, formative assessment includes providing feedback to individual students during a tutorial session amongst the students themselves and between tutor and student, challenging students with questions during lectures, providing feedback on assignments, etc. Formative assessment is essentially regarded as a qualitative exercise as it is 'a feedback process that provides information that can be used to fine-tune or modify what has already been done'. ${ }^{2}$ For example, the written comments made on a student's essay give formative feedback (Fig. 1).
An expanding form of assessment which could be considered as a form of formative assessment is self-assessment, which is the means by which 'students can assess their knowledge and skills to identify their own learning needs.' A very important part of this process is the self-regulation of one's own learning, students understanding how they learn and thereby managing the learning process more effectively. ${ }^{10}$ Self-assessment, according to a number of experts, is a crucial skill for all healthcare professionals. ${ }^{77}$ A flavour of self-assessment is given in one model ${ }^{11}$ (an interactive examination), the aims of which are to evaluate not only students' clinical skills and competence, but also their ability to selfassess their proficiency. It consists of:

- Self-assessment through standardised ordinal scales

- Written answers to a short essay question

- A group discussion.

The students compare their own essay to one written by an 'expert' and deliver a comparison text which identifies all differences in form, content or structure.

In one recent study in a Swedish dental school, it was tested on two groups of undergraduate students. Their selfassessment was matched to the judgement of their instructors and statistically analysed. ${ }^{11}$ The students' acceptance of the methodology was very positive, although they seemed to overestimate their competence in diagnostic skills, but not in treatment skills. In conclusion it was claimed that the interactive examination had potential 'for providing a deeper insight into students' abilities to prioritise, self-assess themselves and steer their learning.' ${ }^{11}$ Another study $^{12}$ used formal assessments and self-assessments with 77 second year dental students and found that although the students' self-assessment grades did not improve from one assessment round to the next, the students did improve their ability to self-assess their own preclinical prosthodontic procedures more accurately.

\section{Summative assessment}

Summative assessment is a more quantitative exercise and can be explained as 


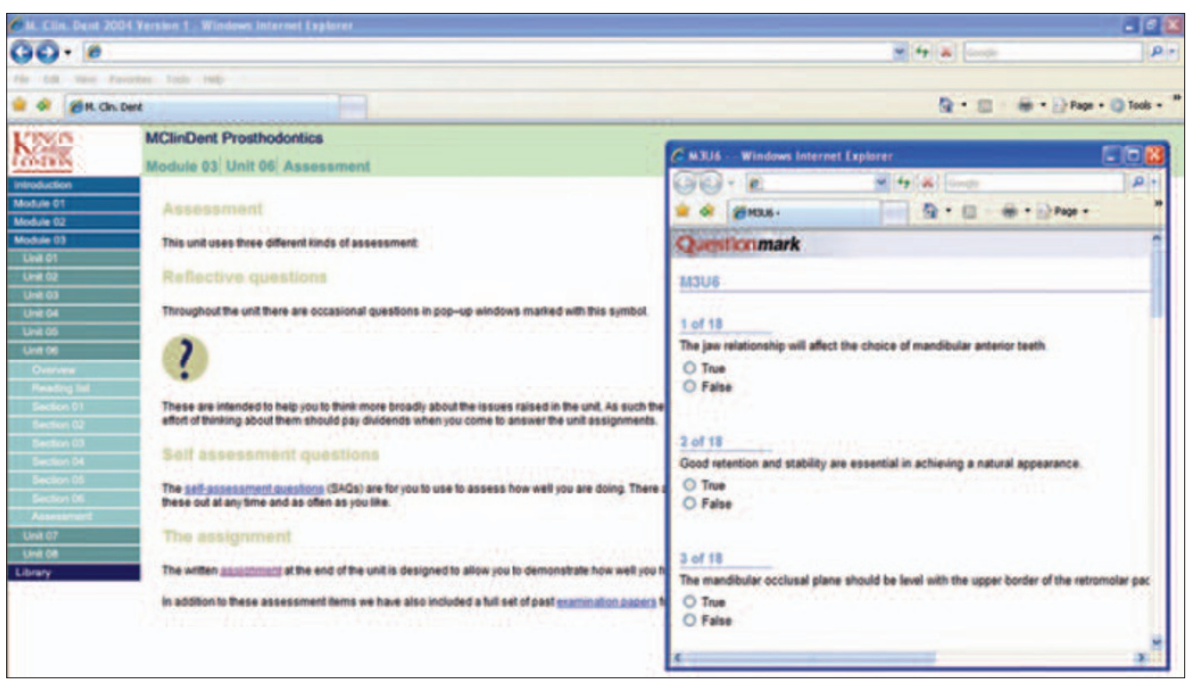

Fig. 1 Examples of CAA used in an online postgraduate course

'a judgement about how well [a student] is doing'. It measures this as the grade given to a student's paper. Some lecturers also use a diagnostic assessment at the beginning of a course which allows them to 'access students' prior knowledge' early in the course and have a more accurate idea of what progress each student has made. Summative assessment is used on many higher education courses and with the increasing numbers of students in single year cohorts, is the main method of assessing what the students have learnt over a period of time.

These assessment types form a body of methods through which the performance of students can be judged and rated as well as improving their learning processes. Interestingly though, a national survey of CAA revealed that on the whole it was being used mostly to support formative assessment, as its use for summative assessment was associated with perceived risks and security issues. ${ }^{13}$

CAA is, therefore, more than just 'a checking device to ascertain what a student knows during key phases of a course of study... it should also form an integral part of the learning process where the personalised feedback provided to students, could promote both better understanding and self-reflection. ${ }^{13}$

\section{METHODS OF ASSESSMENT}

There are various assessment methods in use in HE which can be used as a basis for CAA. The most obvious ones are written, oral and practical examinations, most useful for summative assessment, and the submission of written assignments, which can enable some formative assessment with sufficient feedback.

There is also a group of smaller-scale, yet valuable measures that provide ongoing formative (and self-regulated) assessment. These include multiple choice questions (MCQs), quizzes, crosswords and matching pictures to words; videos of examples (something that paper-based assessments cannot provide); questionnaires; and case histories (Fig. 2). Information technology systems have simplified the preparation and delivery of these through the use of CD-ROMs and the web and increased their potency through the use of multimedia. Most dental schools utilise these systems as part of undergraduate, postgraduate and CPD courses. There is also the promise of virtual reality, which may well allow many practical tests and examinations to be conducted on the web.

Information technology can also play a part in the creation of assessment tests. ${ }^{14}$ Commercial software programs 'allow tutors to create and operate computer-based teaching tests with minimal training. ${ }^{4}$ Computer programs can create questions and organise them into examinations, quizzes, tests or surveys and then deliver them securely via a standard web browser, PDA, CD-ROM, or paper. Questions can be randomised, with instant feedback and on-demand viewing of results, reports and analyses.

On a more comprehensive level, there is the Tripartite Interactive Assessment

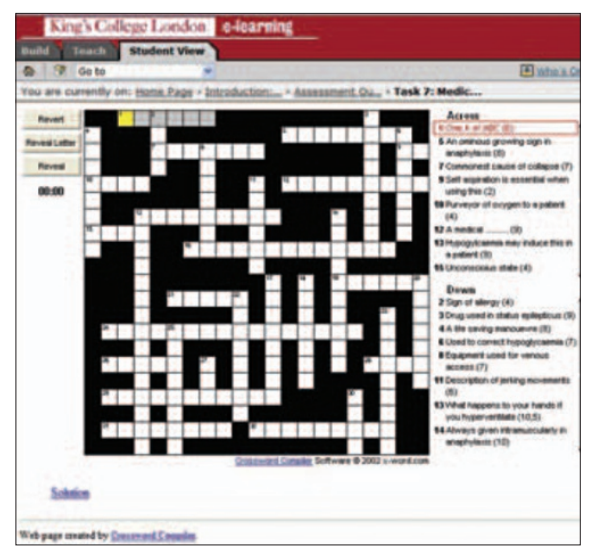

Fig. 2 Example of a crossword used to review the management of medical emergencies in dental practice in an undergraduate course

Delivery System (TRIADS) developed by the University of Derby, which formed the basis of the Assessment of Learning Outcomes project funded by the UK Higher Education Funding Council for England (HEFCE). According to the University's website, ${ }^{15}$ 'One of the advantages of using software authoring tools to produce assessments lies in the wide range of interactivity that they provide coupled with the ability to mix different styles of interaction on a single screen.'

Recent developments are enabling the system to surmount the objections against computer-based assessment (CBA), which include: ${ }^{15}$

- Its inability to deliver only multiplechoice or similar question styles

- The results are unreliable as the styles are susceptible to scoring by guesswork

- CBA is only applicable to low level testing of factual knowledge

- CBA is hardware intensive

- The validation of user identities and security of results are difficult to achieve.

TRIADS claims to "provide the tools to test most aspects of most disciplines given the presence of question designers with sufficient imagination.' ${ }^{15}$

\section{THE APPLICATION OF ICT}

Computers have been in use for assessment for some time but developments in both hardware and software, have increased their applications in this area, as TRIADS reveals. However, one 
commentator raises a note of warning and has suggested that CBA should be seen as part of a wider strategy which enhances the effectiveness of assessment methods employed across the whole degree programme. The key to this is the provision of a balance of assessment methods which test the range of skills, abilities and knowledge required by the learning outcomes. ${ }^{16}$

It has been suggested that 'Technology can be used for assessment purposes at various levels ranging from the management of the assessment of information to a fully-automated assessment system. ${ }^{17}$ The former enables information to be presented in different ways to meet the needs of different audiences' (including teachers and students); while in the latter, 'all aspects of the system, from the assessment which the student completes, to the processing and administration of the marks, including the overall management of assessment information, are technology-based. ${ }^{17}$

Recent examples of the use of ICT to support other forms of assessment include video recording students when they are interacting with patients and applying voice-to-text analysis to these recordings to search to see if the students are using key words in these interactions. ${ }^{18}$ Another aspect of assessment which is enhanced by information technology is 'tracking', ie keeping tabs on what students are doing by, for example, checking the number of times a student logs into a virtual learning environment (VLE); not really 'Big Brother', but a useful guide to their activity and commitment (Fig. 3).

Clinical aptitude testing (CAT) is another form of CAA used in the university application procedure for medicine and dentistry. The UKCAT was developed to ensure a 'level playing field' for applicants from diverse educational and cultural backgrounds. ${ }^{19}$ The test assesses mental abilities and behavioural characteristics deemed suitable for aspiring professionals, that cover verbal, quantitative and abstract reasoning, and decision and non-cognitive analyses. Students may practice the types of tests but cannot actually cram for them as there is no curriculum content. They are now a requirement for admission

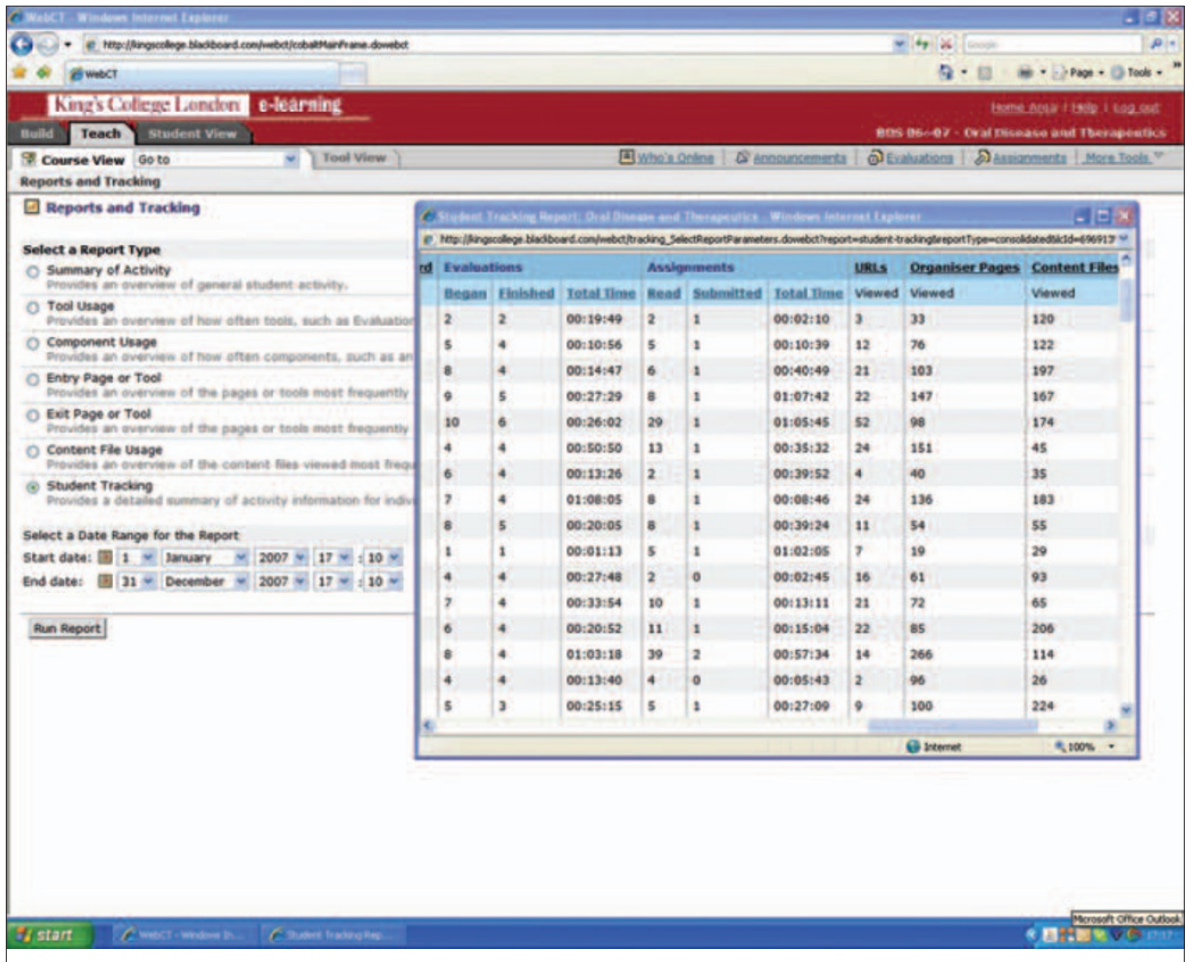

Fig. 3 Feedback from a virtual learning environment tracks student activity in an online course over one year

in many universities where places are keenly contested.

There is substantial research evidence, accumulated over the last 30 years, showing that computer-based simulations can enhance students' learning 20 and can provide an effective method of formative assessment, based on the extensive evidence about formative assessment, some of which is referred to above. ${ }^{7}$ Computer simulations 'can combine mechanical, audiovisual and data resources to create realistic presentations... and offer immediate feedback and correction of errors. ${ }^{4}$ A description of the University of Leiden's Dynamic Patient Simulator (DPS) explains that it simulates the condition of a patient in time while the student can interact with and even treat the patient. ${ }^{21}$ All medical and diagnostic procedures are available to the student and they can influence the condition of the virtual patient, changes to whom can subsequently be seen by the student whose actions are recorded and judged by the system for the final evaluation and score.

The benefits of computed-assisted summative assessment have been summarised $^{22}$ as:

- Large numbers of assessments can be marked quickly and accurately
- Student responses to questions can be monitored

- Assessments can be provided within an open-access system

- Assessments can be stored and re-used

- Assessment items can be randomly selected to provide a different paper for each student

- Adaptive testing can reduce the number of test items required to assess student knowledge

- Immediate feedback on performance and advice can be provided (this last benefit being more formative than summative).

By contrast, there are a number of potential drawbacks, one being that it "cannot be used effectively to measure higher order thinking. ${ }^{13}$ However, from the evidence we have referred to above about formative and self-regulated assessment, we do not agree with this last point because there are many additional benefits of CAA to those above including displaying higher order thinking. For example, students can:

- Receive ongoing feedback to their knowledge and skills and learning progression

- Share ideas and challenge their own and each others' thinking 
- Check their knowledge against expert online information

- Monitor their learning strategies and master their learning procedures

- Discover weaknesses in knowledge and skills early on in their courses

- Improve their study skills.

The authors also identify other barriers to using CAA, namely:

- The additional time and effort required for the development and management of CAA

- Ensuring that the students' data is secure

- Stress caused for students who feel threatened by using online and other CAA

- Many IT assessment tools are still rudimentary. ${ }^{13}$

Nevertheless, it is possible that developments such as TRIADS may well eliminate these problems. In addition, students seem to enjoy the experience. One example comes from The Open University's 'Maths for science' short course, which 'not only offered students a webbased examination in their own home, but also provided them with immediate feedback and assistance when they submitted their individual answers to each question. ${ }^{14}$ The marking regime was structured so that a correct answer at the first attempt was awarded 100\% of marks, while success following a text hint as to the correct answer earned $65 \%$, with 35\% awarded after two text hints. 'All students managed to complete the examination, found it easy to use and felt they learnt a lot with this format, especially when reasoning for each correct answer was revealed. They were also pleased to obtain partial credit for their answers. ${ }^{23}$

Apart from displaying how electronic means of delivery can create different, fairer and more flexible assessment types, the approach also 'reduced the amount of time required to process results and awards. ${ }^{23}$

However, too much reliance should not necessarily be placed on web-based solutions. A new knowledge assessment technique devised to handle an increasing number of students at Zagreb University was judged, after statistical analysis, to have shown "no significant difference between final grades before and after the introduction of [the] computerized method,' although there was a benefit of time-saving for the examiners. ${ }^{24}$

\section{PLAGIARISM}

Not all the effects of ICT on assessment are beneficial, as it is thought to encourage plagiarism.

The biggest problem with plagiarism is in relation to coursework undertaken outside the examination room, or away from a classroom or campus, where invigilation is virtually impossible. The University of East London defines plagiarism as 'The submission of material (written, visual or oral) originally produced by another person or persons without due acknowledgement, so that work could be assumed to be the student's own'. ${ }^{25}$

Difficulties arise with deciding what constitutes plagiarism, collusion ('deliberately and actively working together with one or more others with the purpose of deceiving third parties') ${ }^{26}$ or indeed, just plain cheating by using someone else's published materials. In a report for the Joint Information Systems Committee (JISC), the University of Luton found that "the main source of plagiarised material encountered by academics came from textbooks and theses. Work cut and posted from the Internet was ranked second as a source. ${ }^{27}$

According to a study by the Qualifications and Curriculum Authority (QCA), the number of fraud cases is growing in schools, with 3,500 teenagers caught in 2004 , a rise of $9 \%$ over $2003 .{ }^{28}$ The JISC conducted a national plagiarism survey of HE institutions in November 2004. Some 114 higher education institutions responded, representing nearly two thirds of the higher education institutions in the UK. Nearly all (97\%) responded that plagiarism was a problem in general in HE, with $72 \%$ of the respondents believing that it was a problem within their institution. ${ }^{29}$

The Internet is making the situation worse. Through it, students can download large chunks of uncredited material for incorporating into their own assignments. Worse, they have access to websites offering customised essays: the QCA lists at least ten popular sites producing coursework from GCSE to degree levels and comments that 'With so much work being completed outside school, the use of such sites cannot be controlled. ${ }^{30}$

The same authors suggest that there are several reasons for students plagiarising their work, which they generalise under the headings: ${ }^{30}$

- Widening participation and the move to mass continued education

- Introduction of course fees and the elimination of grants

- The growth of the Internet and the resources available.

What are the solutions to the problem? Firstly, there is the tutors' intuition. Most tutors get to know each individual student's style of writing, thinking, terminology and discussing, and their levels of knowledge. This personal check should not be underestimated for as has been observed, 'technology can only assist us, it will never replace the expertise of humans and the answer lies in process and procedures, not technology alone. ${ }^{30}$

Plagiarism - a good practice guide advises that educational institutions should establish a set of policies and programme expectations that include a definition of plagiarism and the disciplinary penalties for indulging in this, and that this should be communicated to all students and staff. ${ }^{30}$ The Guide also lists a set of ideas for 'designing out opportunities for plagiarism'. Summarised, these include:

- Changing assessments every year

- Devising learning outcomes that require analysing, evaluation and synthesis

- Creating individualised tasks

- Integrating assessment tasks

- Setting a range of assessment tools that require student effort

- Adopting a set of policies and programme expectations.

From its title, JISC's Electronic plagiarism detection project implies that there are technological solutions available. ${ }^{29}$ The most relevant to this discussion are 'free text' software programmes for essays and dissertations. The University of Luton tested a number of 
commercial products and services for their effectiveness for JISC. ${ }^{27}$ Some of these 'are designed to detect material cut and pasted from the Internet, while others detect instances of identical or very similar submissions. Some services have the facility to compile databases and so build-up a repertoire of assignments and material that have been purchased from paper-mills and essay-banks.' The report, however, found that such systems and services 'are limited to detecting instances of material cut and pasted from the Internet, instances of collusion and reliance on capture technologies for detecting text books and paper-mill submissions. ${ }^{27}$ Software such as Turni$\operatorname{tin}^{\mathrm{TM} *}$ is now becoming widely used by HE across the world, but students must agree to this as part of the assessment process. Some universities have tried other strategies of engendering a nocheating culture by stimulating learning to engage the student. ${ }^{31}$ It has also been pointed out that "computer-based tests in the form of examination questions presented to a whole cohort of students in a computer laboratory can be difficult to invigilate. ${ }^{4}$ One problem, which makes it possible for students to cheat, is that computer screens are usually upright. As a result, candidates may be able to see each other's screens, which is an inducement for a quick glance at a contemporary's computer, especially during a written examination, resulting in students cheating. However, this can be overcome by randomly generated questions so that no two adjacent screens are the same.

\section{CONCLUSIONS}

This paper began with a review of the assessment methods used in HE which form an essential part of the education of students. Formative and summative assessments are both needed to assess students' learning and progression. Many advantages for using CAA have been identified which could not only improve the consistency and reliability of end of course assessments, but also enrich the learning progression of the students to counteract the

${ }^{*}$ Turnitin $^{\text {TM }}$ digital assessment suite, viewable at http://turnitin.com/static/home.html. decline of traditional formative assessment methods in HE. ${ }^{3}$ Previous papers ${ }^{7,32}$ have shown the wide range of uses of ICT which can enhance the teaching and learning methods in dental education as discussed above. They are supported by evidence from research into the importance of formative assessment and selfregulated learning. ${ }^{33}$

In the case of summative assessment, Odell et $a .^{34}$ have identified a range of advantages and in a recent study of the acceptability and fairness of online multiple choice questions in human disease and oral disease courses compared to print-based examinations, the researchers actually suggested that online testing was preferred by students, who were more able to scroll back and reflect on their answers before submitting them. ${ }^{34}$

That ICT can make assessment less of an arduous task, not least for the teacher, is undoubted. Detection of plagiarism has been made easier with the use of new technology. It can be concluded that, in the final analysis, computer-assisted assessment has an important part to play in dental education, but the role of a live assessor is still a valuable tool and is of paramount importance.

1. Farrell G, Farrell V, Leung Y K A. Comparison of blackboard CAA and an innovative self assessment tool for formative assessment. Loughborough University Institutional Repository, 2005. www. dspace.lboro.ac.uk (accessed on 8 April 2008).

2. Black P, William D. Assessment and classroom learning. Assessment in Education 1998; 5: 7-71.

3. Gibbs G. Why assessment is changing. In Bryan $\mathrm{C}$, Clegg K (eds) Innovative assessment in higher education. pp 11-22. London: Routledge, 2006.

4. Cantillon C, Irish B, Sales D. Using computers for assessment in medicine. BMJ 2004; 329: 606-609.

5. Testing times. The newsletter of the Computer Assisted Assessment Centre 1999; 1: 1.

6. Boston K. Delivering assessment - a fair deal for learners. Speech given at Royal Festival Hall, London, UK on 20 April 2004. Cited by Chapman G. Drivers and barriers to the adoption of computer assisted assessment for UK awarding bodies. pp 3. Proceedings of 9th CAA conference 2005. http://www.caaconference.com/pastConferences/2005/proceedings/ChapmanG.pdf (accessed 8 April 2008).

7. Eaton K A, Reynolds P A, Cox M J. Top of the pops - CD-ROM and DVDs in dental education. Br Dent $J$ 2008; 204: 203-207.

8. Joint Information Systems Committee. e-Assessment glossary (extended). London: JISC, 2006. http://www.jisc.ac.uk/uploaded_documents/ eAssess-Glossary-Extended-v1-01.pdf (accessed 8 April 2008).

9. Harlen W, James M. Assessment and learning: differences and relationships between formative and summative assessment. Assessment in Education 1997; 43: 365-379.

10. Boekaerts M, Corno L. Self-regulation in the classroom: a perspective on assessment and intervention. Appl Psychol 2005; 54: 199-231.

11. Mattheos N, Nattestad A, Schittek-Janda M, Attström R. A structured examination approach for assessing students' self-assessment skills. J Dent Res 2003; 82 (Spec Iss B): Abstract 2402.

12. Curtis $D A$, Lind $S L$, Dellinges $M$, Setia G, Finzen $F$ C. Dental students' self-assessment in preclinical examinations. J Dent Educ 2008; 72: 265-277.

13. Warburton W, Conole G. CAA in UK HEls - the state of the art? Proceedings of the 7th CAA Conference 2003. http://www.caaconference.com/ pastConferences/2003/procedings/warburton.pdf (accessed 8 April 2008).

14. Whitelock D. Electronic assessment: marking, monitoring and mediating learning. Int J Learning Technol 2006; 2: 264-276.

15. University of Derby. Tripartite Interactive Assessment Delivery System (TRIADS). http://www. derby.ac.uk/assess/newdemo/triadshistory.html (accessed 8 April 2008).

16. Bull J, McKenna C. Blueprint for computer-based assessment. New York: Routledge, 2003.

17. Mogey N, Watt H. The use of computers in the assessment of student learning. In Stoner G (ed) Implementing learning technology. Edinburgh: Learning Technology Dissemination Initiative, Herriot-Watt University, 1999.

18. Kim Y, Ahronheim J, Suzuka K et al. Enterprise digital asset management system (DAMS) pilot: lessons learned. Inf Technol Libraries 2007; 26: 4-16.

19. UKCAT Consortium. Validity and reliability webpage. http://www.ukcat.ac.uk/pages/ details.aspx?page=ValidityReliability (accessed 10 May 2008)

20. Cox M J, Abbott C (eds). A review of the research literature relating to ICT and attainment. London: DfES, 2003. http://partners.becta.org.uk/uploaddir/downloads/page_documents/research/ict_ attainment04.pdf (accessed 8 May 2008).

21. Bloemendaal PM, Schoonderwaldt E M. Measuring medical competence with the Dynamic Patient Simulator. http://www.malts.ed.ac.uk/ALTC/submissions/upload/Blo69/Sub=Blo69.doc (accessed 8 April 2008).

22. Harwood I. When summative computer-aided assessments go wrong: disaster recovery after a major failure. Br J Educ Techno/ 2005; 36: 587-597.

23. Whitelock D, Raw Y. Taking an electronic mathematics examination from home: what the students think. In Constantinou C P, Zacharia Z C (eds) Computer based learning in science volume 1 New technologies and their applications in education. pp 701-703. Nicosia, Cyprus: Department of Educational Sciences, University of Cyprus, 2003. ISBN 9963-8525-1-3.

24. Illes D, Alajbeg I, Valentic-Peruzovic M. Computerized knowledge assessment in dental education. J Dent Res 2003; 82 (Spec Iss B): Abstract 2399.

25. University of East London. Manual of general regulations part 8: assessment offences. Section 1.1(e). London: University of East London, 2007. http://www.uel.ac.uk/qa/manual/documents/ PART8-AssessmentOffences-Amended-November2007.doc (accessed 29 May 2008).

26. Johnston B. The concept of plagiarism. Learning and Teaching in Action 2003; 2(1). http://www. celt.mmu.ac.uk/Itia/issue4/johnston.shtml (accessed 29 May 2008).

27. Bull J, Collins C. Coughlin E, Sharp D. Technical review of plagiarism detection software report. Luton, UK: University of Luton and Computer Assisted Assessment Centre, 2001. www.jisc. ac.uk/uploaded_documents/luton.pdf (accessed 28 November 2005).

28. Qualifications and Curriculum Authority. A review of GCE and GCSE coursework arrangements. London: Qualifications and Curriculum Authority, 2005. http://www.qca.org.uk/libraryAssets/media/ qca-05-1845-coursework-report.pdf (accessed 28 November 2005).

29. Chester G. Plagiarism, detection and prevention. Final report on the JISC Electronic Plagiarism Project. London: JISC, 2001. http://www.jisc. ac.uk/media/documents/programmes/plagiarism/ plagiarism.pdf (accessed 8 April 2008). 
30. Carroll J, Appleton J. Plagiarism. A good practice guide. Oxford: Oxford Brookes University, 2001. http://www.jisc.ac.uk/media/documents/programmes/plagiarism/brookes.pdf (accessed 8 April 2008)

31. Dawson J. Plagiarism: what's really going on? In Seeking educational excellence. Proceedings of the 13th Annual Teaching and Learning Forum, 9-10 February 2004. Perth, Western Australia:
Murdoch University, 2004. http://Isn.curtin edu.au/tlf/tlf2004/dawson.html (accessed 24 February 2007)

32. Reynolds PA, Cox M J, Dunne S, Myint Y K, Harpe J. Portable digital assistants (PDAs) in dentistry: part II - pilot study of PDA use in the dental clinic BrDent J 2007: 202: 477-483.

33. Greene J A, Azvedo R. A theoretical review of Winne and Hadwin's model of self-regulated learning: new perspectives and directions. Rev Educ Res 2007; 77: 334-372.

34. Odell E, Reynolds PA, Cox M J, Newton J T, Escudier M, Pitt-Ford T R. Online examinations: questions of design, acceptability and fairness. In Profile 2006. pp 5. London: King's College London Dental Institute, 2006. http://www.kcl. ac.uk/content/1/c6/02/34/87/2006.pdf (accessed 9 April 2008). 